\title{
MESIN ROLL PELAT BAHAN PEWTER
}

\author{
Rodika $^{1}$, Agung Supriyadi ${ }^{2}$, Indra Anggriawan ${ }^{3}$ Sutiryo $^{4}$ \\ Politeknik Manufaktur Negeri Bangka Belitung \\ Kawasan Industry Air Kantung Sungailiat Bangka 33211 \\ Telp. 0717-93586, 95252 \\ Faks. 071793585 \\ rrodika@ymail.com
}

\begin{abstract}
The design of the machine roll plate made from pewter to be developed is a machine that is simple, easy to be usde and does not endanger the user and use 1 phase ac motors. The system uses two cylinder rolls at the top and bottom with a thickness regulator by using a screw system. The material used is steel st. 40 for the roll materials and to get the smooth rolling process, then roll grinding cylinder. For the power cylinder roll will be analyzed by the software that is to know the voltage that occurs in the cylinder roll when rolling the pewter plate by assumed load of $1000 \mathrm{~kg}$. The result of this research is the engine may roll the plate pewter with a size of $260 \mathrm{~mm} \times 70 \mathrm{~mm} \times 3 \mathrm{~mm}$ to a size of $430 \mathrm{~mm} \times 77 \mathrm{~mm} \times 1$ $\mathrm{mm}$, which takes 6 minutes of 1 plate pewter, plate surface pewter solid and smooth, and the size of the plate length increases $\pm 98 \%$ and $\pm 7 \%$ width, thus saving time, effort and cost in the casting process.
\end{abstract}

Keywords: Roll Machine, AC motors, Pewter Plates.

\begin{abstract}
Abstrak
Rancangan mesin roll berbahan pelat pewter yang akan dikembangkan ini adalah mesin yang sederhana, mudah digunakan dan tidak membahayakan penggunanya serta menggunakan motor ac 1 phase. Sistem pengerollan menggunakan dua buah silinder atas dan bawah dengan pengatur ketebalan menggunakan sistem ulir. Material yang digunakan baja st. 40 untuk bahan roll dan untuk mendapatkan hasil pengerollan yang halus, maka silinder roll digerinda. Untuk kekuatan silinder roll akan dianalisa dengan menggunakan bantuan software yaitu untuk mengetahui tegangan yang terjadi pada silinder roll pada saat mengerol pelat pewter dengan beban pengerollan diasumsikan sebesar $1000 \mathrm{~kg}$. Hasil penelitian ini adalah mesin dapat pemipihkan plat pewter dengan ukuran $260 \mathrm{~mm} \times 70 \mathrm{~mm} \times 3 \mathrm{~mm}$ menjadi ukuran $430 \mathrm{~mm} \times 77 \mathrm{~mm} \times 1 \mathrm{~mm}$ membutuhkan waktu 6 menit untuk 1 plat pewter, permukaan pelat pewter padat dan halus, serta ukuran pelat bertambah panjang $\pm 98 \%$ dan lebar $\pm 7 \%$, sehingga dapat menghemat waktu, tenaga dan biaya pada proses pengecoran.
\end{abstract}

Kata kunci: Mesin Roll, Motor AC, Pelat Pewter.

\section{PENDAHULUAN}

Pewter adalah paduan logam antara timah putih (Sn), Antimon (Sb), dan tembaga (Cu), dengan kandungan bervariasi. Pewter sendiri biasanya dibuat suatu kerajinan tangan dengan bentuk seperti gantungan kunci, patung, plakat, kapal layar dan lain-lain. Dari hasil survei yang dilakukan pada salah satu pengrajin pewter yaitu Bapak Sugiono yang beralamat di Jl. Depati Hamzah Gg. Kalamaya Semabung lama. Contohnya dalam proses membuat kerajinan kapal layar dibutuhkan pelat lembaran pewter dengan ukuran $260 \times 70 \times 3 \mathrm{~mm}$, prosesnya adalah dari pelat dengan ukuran $260 \times 70 \times 3 \mathrm{~mm}$ dilakukan pengikisan dan pengamplasan, ini semua dikerjakan secara manual, kedua proses ini memakan waktu sampai 15 menit. Setelah selesai diproses hasilnya belum tentu sesuai dengan keinginan yaitu pelat dengan permukaan yang halus dan kerataan bidang yang sama.

Dari permasalahan di atas, dibuatlah mesin roll plat pewter yang dapat digunakan untuk membantu pengrajin pewter dalam membuat beberapa produk yang berbentuk pelat pewter dengan 
ukuran $400 \mathrm{~mm} \times 150 \mathrm{~mm} \times 1 \mathrm{~mm}$ dengan harapan dapat mempermudah dan mempersingkat waktu proses pemipihan plat.

\section{METODE PENELITIAN}

Dalam penelitian ini, dibuat tahapan penyelesaiannya seperti pada skema atau bagan alir yang dapat dilihat Gambar 2.1.

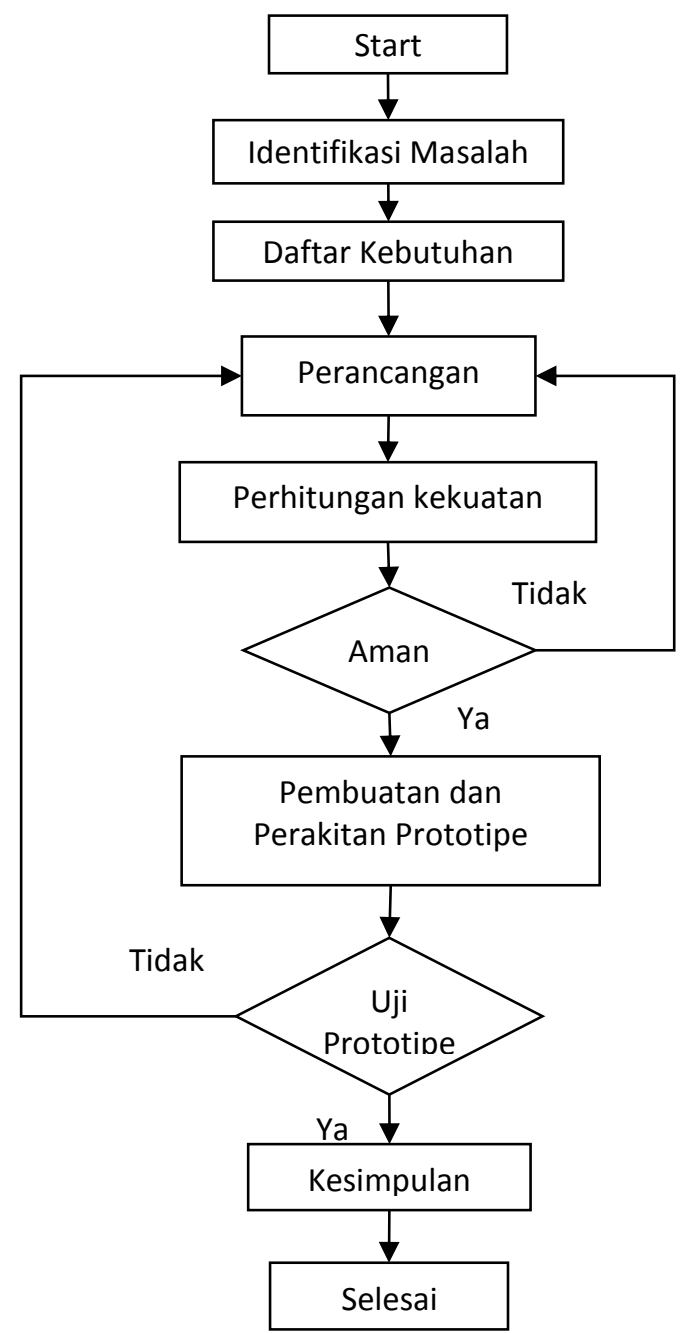

Gambar 2.1 Diagram Penelitian

\section{HASIL DAN PEMBAHASAN}

\subsection{Penyusunan Daftar Kebutuhan}

Dalam perancangan suatu produk, untuk mendapatkan hasil produk yang baik tidak lepas dari pelanggan/konsumen. Peran serta konsumen ini adalah agar produk yang dihasilkan sesuai dengan permintaan dari konsumen. Langkah awal dalam pembuatan produk ini adalah membuat daftar kebutuhan. Berikut ini daftar kebutuhan mesin roll pelat pewter yang dapat dilihat pada tabel 3.1, dibawah ini:

Tabel 1. Daftar kebutuhan produk

\begin{tabular}{lc}
\hline \hline & $\begin{array}{c}\text { Daftar kebutuhan produk } \\
\text { Mesin Roll Pelat Bahan Pewter }\end{array}$ \\
\hline No & Uraian Kebutuhan \\
\hline 1 & Sistem roll menggunakan dua silinder \\
\hline 2 & Mengunakan motor ac 1 phase \\
\hline
\end{tabular}




\begin{tabular}{ll}
\hline \hline 3 & Bahan Pelat pewter $300 \times 100 \times 3 \mathrm{~mm}$ \\
\hline 4 & Hasil pelat sesudah diroll ketebalannya $1 \mathrm{~mm}$ \\
\hline 5 & Jarak kedua roll dapat diatur \\
\hline 6 & $\begin{array}{l}\text { Kuat dan Aman: } \\
\text { a. Kuat menahan beban } \\
\text { b. Tidak mudah rusak }\end{array}$ \\
\hline
\end{tabular}

\subsection{Perancangan}

Pada proses perancangan ada 3 hal yang penting untuk memenuhi kebutuhan/permintaan akan produk yang sesuai dengan keinginan konsumen yaitu kualitas, waktu, dan biaya produk. Ketiga hal ini harus menjadi pertimbangan dalam merancang suatu produk. Rencana desain konsep mesin roll yang akan dibuat dapat dilihat pada gambar 3.2.

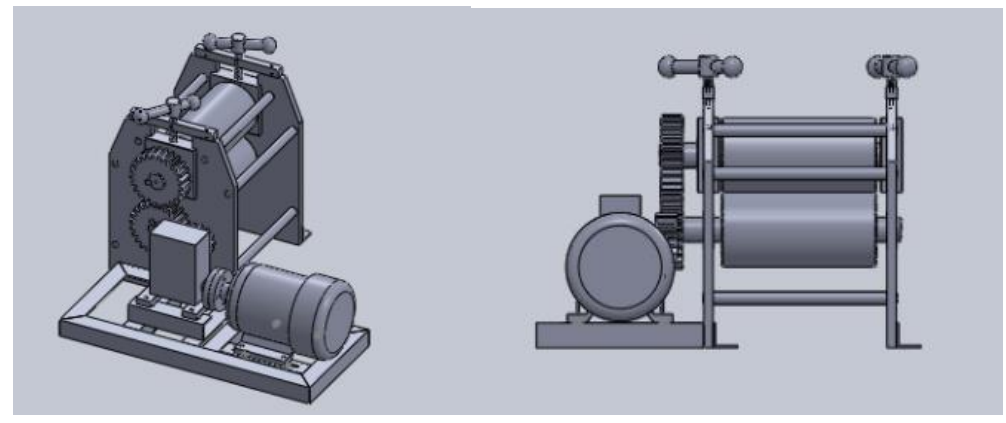

Gambar 3.2. Mesin Roll Pelat Bahan Pewter

Konsep ini dilengkapi dengan dua buah roll yang terdiri dari roll atas dan bawah. Posisi motor diletakkan disamping, transmisi menggunakan roda gigi dan reduser gearbox. Posisi tuas penyetel ketebalan pelat berada di atas dam menggunakan sistem ulir.

\subsection{Pembuatan Komponen}

Pada tahap ini ada beberapa bagian mesin yang harus dikerjakan melalui proses pemesinan seperti proses bubut, frais, bor dan las, serta beberapa bagian yang harus dibeli seperti motor, reduser dan baut.

\subsection{Perakitan(assembling)}

Proses perakitan merupakan proses penggabungan bagian bagian dari komponen satu dengan komponen yang lainnya sehingga menjadi sebuah mesin yang utuh. Pada tahap ini komponenkomponen mesin yang telah dibuat dirakit sesuai dengan gambar.

Tahapan dalam perakitannya dimulai dari konstruksi rangka, pemasangan bearing, hingga reduser, dan kopling serta motor listrik. Hasil dari perakitan mesin dilihat pada Gambar 3.4.

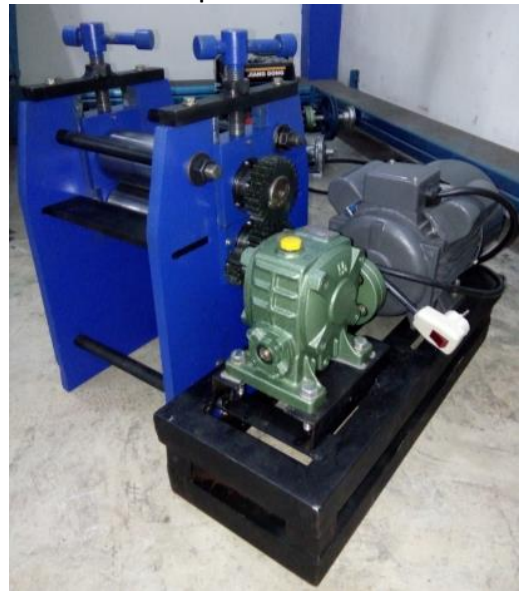

Gambar 3.4. Hasil perakitan mesin roll plat pewter 


\subsection{Uji Coba}

Setelah perakitan selesai, pada tahap ini dilakukan proses uji coba pada mesin roll plat pewter. Uji coba dilakukan bertujuan untuk mengetahui hasil output dari mesin yang telah dirakit serta untuk mengetahui masalah yang terjadi pada saat mesin di uji coba. Hasil pelat pewter yang belum dan sudah di pipihkan dapat dilihat pada gambar 3.5.1 dan 3.5.2. Adapun hasil dari uji coba mesin yang sudah dilakukan dapat dilihat pada tabel 3.5.1dan tabel 3.5.2 berikut ini.

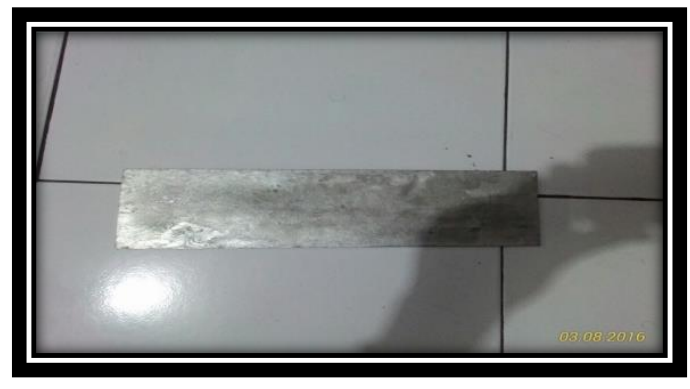

Gambar 3.5.1 Pelat pewter sebelum pemipihan

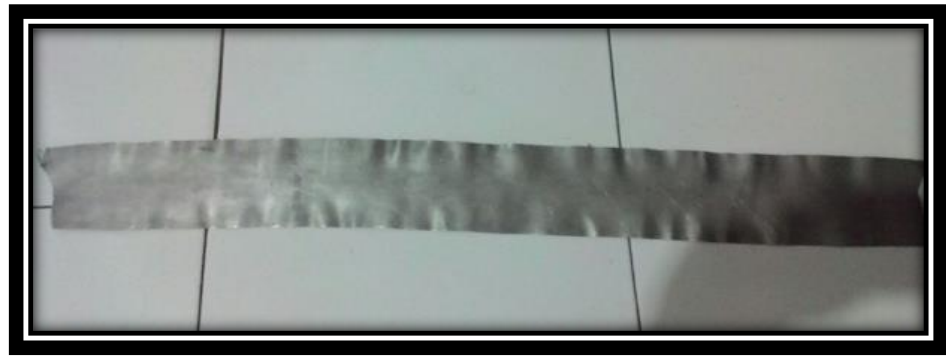

Gambar 3.5.2 Hasil plat pewter setelah pemipihan

Tabel 2. Data uji coba 1 dengan ukuran pelat pewter $260 \times 71 \times 3 \mathrm{~mm}$

\begin{tabular}{cccc}
\hline No & Hasil Pemipihan & Ukuran Pengurangan & Keterangan \\
\hline 1 & $290 \times 73 \times 2,2$ & 0,8 & 7 kali pemipihan \\
\hline 2 & $312 \times 75 \times 1,4$ & 0,8 & 7 kali pemipihan \\
\hline 3 & $330 \times 76 \times 1,2$ & 0,12 & 7 kali pemipihan \\
\hline 4 & $335 \times 76 \times 1,2$ & 0,08 & 7 kali pemipihan \\
\hline 5 & $405 \times 76,5 \times 1,1$ & 0,1 & 7 kali pemipihan \\
\hline 6 & $430 \times 77 \times 1$ & 0,1 & 7 kali pemipihan \\
\hline
\end{tabular}

Tabel 3. Data uji coba 2 dengan ukuran pelat pewter $271 \times 74 \times 2,4 \mathrm{~mm}$

\begin{tabular}{cccc}
\hline No & Hasil Pemipihan & Ukuran Pengurangan & Keterangan \\
\hline 1 & $295 \times 74,8 \times 1,74$ & 0,66 & 10 kali pemipihan \\
\hline 2 & $345 \times 75 \times 1,5$ & 0,24 & 10 kali pemipihan \\
\hline 3 & $345 \times 75 \times 1,41$ & 0,09 & 10 kali pemipihan \\
\hline 4 & $350 \times 75 \times 1,4$ & 0,01 & 10 kali pemipihan \\
\hline 5 & $385 \times 75 \times 1,1$ & 0,3 & 10 kali pemipihan \\
\hline 6 & $525 \times 78 \times 0,64$ & 0,46 & 10 kali pemipihan \\
\hline
\end{tabular}

Setelah melakukan uji coba mesin, maka diperoleh hasil analisa bahwa waktu yang dibutuhkan untuk pemipihan plat pewter dengan ukuran $260 \mathrm{~mm} \times 71 \mathrm{~mm} \times 3 \mathrm{~mm}$ dan $271 \mathrm{~mm} \times 74 \mathrm{~mm} \times 2,4 \mathrm{~mm}$ hingga ketebalannya menjadi $1 \mathrm{~mm}$ dengan pertambahan panjang dan juga lebar uji coba pertama dan kedua $430 \mathrm{~mm} \times 77 \mathrm{~mm}$ dan $625 \mathrm{~mm} \times 78 \mathrm{~mm}$ memerlukan waktu kurang lebih 6 menit. Ketebalan yang dihasilkan dari 6 titik pengukuran masih masuk dalam toleransi $(0,3 \mathrm{~mm})$. Untuk 1 kali reduksi, plat pewter harus dipipihkan rata-rata sebanyak 4 kali. Proses pemipihan menggunakan mesin roll plat pewter dapat menambah panjang plat pewter Plat pewter $98 \%$ dan lebar $7 \%$. 


\section{SIMPULAN}

Berdasarkan hasil uji coba yang sudah dilakukan terhadap mesin roll pelat pewter dapat diambil kesimpulan sebagai berikut:

1. Mesin roll pelat pewter mampu melakukan pemipihan plat pewter dengan ukuran $260 \mathrm{~mm} \times 70$ $\mathrm{mm} \times 3 \mathrm{~mm}$ menjadi ukuran $430 \mathrm{~mm} \times 77 \mathrm{~mm} \times 1 \mathrm{~mm}$ membutuhkan waktu 6 menit untuk 1 plat pewter.

2. Dari hasil pengukuran di 6 titik masih tidak terlalu besar perbedaanya yaitu $0,3 \mathrm{~mm}$, sehingga pemipihan pelat masih masuk toleransi untuk ketebalan.

3. Permukaan dari pelat pewter padat dan halus.

4. Ukuran pelat bertambah panjang $\pm 98 \%$ dan lebar $\pm 7 \%$, sehingga dapat menghemat waktu, tenaga dan biaya pada proses pengecoran.

\section{DAFTAR PUSTAKA}

[1]. Batan, I.M. L., Desain Produk, Edisi pertama, Penerbit Guna Widya, Surabaya, 2012.

[2]. Pramono Budi, Pelatihan Dasar Pewter. Pangkal Pinang, 2007.

[3]. Endang, Sri, "Sejarah Peleburan Timah Muntok"dalam Majalah Stannia. Mei. Hal 2-25, 2012.

[4]. Heidhus, Timah Bangka dan Lada Muntok. Jakarta: Penerbit Yayasan Nabil, 2008.

[5]. Erman, Erwiza, Menguak Sejarah Timah Bangka-Belitung. Jakarta: Pustaka Nasional PTE LTD, 1999. 